Second Phase Precipitation in As-Welded and Solution Annealed Alloy 22 Welds

B. S. El-Dasher, S. G. Torres

January 13, 2005

ASME Pressure Vessels \& Piping Conference Denver, CO, United States July 17, 2005 through July 21, 2005 
This document was prepared as an account of work sponsored by an agency of the United States Government. Neither the United States Government nor the University of California nor any of their employees, makes any warranty, express or implied, or assumes any legal liability or responsibility for the accuracy, completeness, or usefulness of any information, apparatus, product, or process disclosed, or represents that its use would not infringe privately owned rights. Reference herein to any specific commercial product, process, or service by trade name, trademark, manufacturer, or otherwise, does not necessarily constitute or imply its endorsement, recommendation, or favoring by the United States Government or the University of California. The views and opinions of authors expressed herein do not necessarily state or reflect those of the United States Government or the University of California, and shall not be used for advertising or product endorsement purposes. 


\section{SECOND PHASE PRECIPITATION IN AS-WELDED AND SOLUTION ANNEALED ALLOY 22 WELDS}

\author{
Bassem S. El-Dasher \\ Lawrence Livermore National Laboratory, \\ 7000 East Avenue, L-631, Livermore, CA 94550
}

\section{ABSTRACT}

The precipitation characteristics of tetrahedrally closepacked (TCP) phases during the welding and the subsequent solution annealing process of Alloy 221 1/2" thick plate double-U prototypical welds are investigated. Electron backscatter diffraction (EBSD) was used to provide large scale microstructural observation of the weld cross section, and scanning electron microscopy (SEM) was used to map the location of the TCP phases. Analysis shows that TCP precipitation occurs congruent to the weld passes, with the solution annealing reducing the sizes of coarser precipitates.

Keywords: nuclear waste container, N06022, electron backscatter diffraction, TCP phases.

\section{INTRODUCTION}

Alloy 22 (UNS N06022) is a nickel-based alloy containing approximately $22 \%$ chromium, $13 \%$ molybdenum, $3 \%$ iron, and $3 \%$ tungsten. It has been selected as the candidate material for the outer barrier of the nuclear waste containers for the potential repository site at Yucca Mountain, Nevada [1,2] primarily due to its excellent resistance to pitting and crevice corrosion, as well as stress corrosion cracking [3-8]. However, Alloy 22 welds are known to form potentially detrimental tetrahedrally close packed (TCP) phases upon solidification [9]. Considering that multiple welds are required for the construction of the waste package outer barrier, an understanding of the effect of welding on TCP phase formation is important. This is particularly true since previous experiments on Alloy 22 specimens artificially aged at high temperatures have shown a decrease in corrosion performance and mechanical properties [10], apparently due to TCP phase formation. Further, the effect of solution annealing conditions at the manufacturer recommended temperature of $1121^{\circ} \mathrm{C}$ $\left(2050^{\circ} \mathrm{F}\right)[11]$ on the TCP phases is not known.

In this work, the cross section of thick prototypical welds are investigated in the as-welded and solution annealed conditions $\left(1121^{\circ} \mathrm{C}\right.$ for 20 minutes) in order to determine the effects of welding and solution annealing on TCP phase formation and microstructure.

\section{EXPERIMENTAL METHODS}

1 1/2" thick plate double-U Alloy 22 prototypical welds were used in the study with two $1 / 2$ " thick specimens cut from weld. To simulate the solution annealing conditions, one of the

\author{
Sharon G. Torres \\ Lawrence Livermore National Laboratory, \\ 7000 East Avenue, L-631, Livermore, CA 94550
}

specimens was annealed in an air furnace for 20 minutes at $1121^{\circ} \mathrm{C}$ and water quenched. The weld cross section of both specimens was metallographically prepared by grinding to 1200 grit silicon carbide and polishing to $0.02 \mu \mathrm{m}$ colloidal silica. The specimens were imaged using an FEI Company Quanta 200 scanning electron microscope (SEM) in backscatter mode to determine the location of the TCP phases, and then examined by electron backscatter diffraction (EBSD) to map the microstructure. Figure 1 illustrates schematically the specimen region studied.

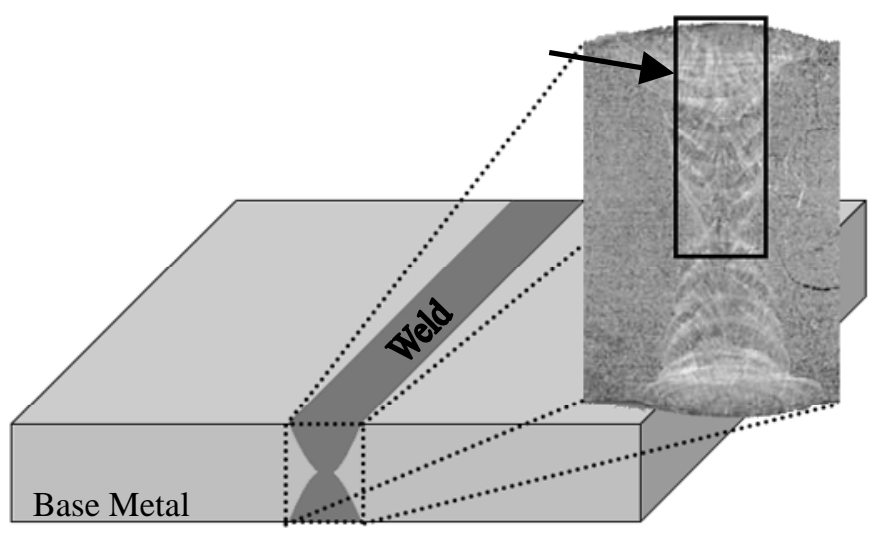

Figure 1. Schematic of weld cross-sectional area examined (arrow).

\section{TCP Phase Imaging}

Due to the compositional differences between the TCP phases and the weld matrix [9], a solid-state backscatter electron detector is best suited for imaging the TCP phases. Figure 2 represents a micrograph obtained using a backscatter detector, illustrating how the TCP phase precipitates appear white in the micrograph, and thus allowing for easier analysis.

To map the weld from top to center, 880 backscatter images were collected for each specimen at a magnification of $500 x$, and merged into a collage of 44 rows by 20 columns. At this magnification the field of view of each image corresponds to $511 \mu \mathrm{m}$ by $441 \mu \mathrm{m}$. To ensure no overlap between images, the stage was stepped in $520 \mu \mathrm{m}$ and $450 \mu \mathrm{m}$ translations in the $\mathrm{x}$ 
and y directions, respectively, and the differences between the steps and image sizes were accounted for during the collage generation procedure. The total area covered for each specimen is $10.4 \mathrm{~mm}$ by $19.8 \mathrm{~mm}$.

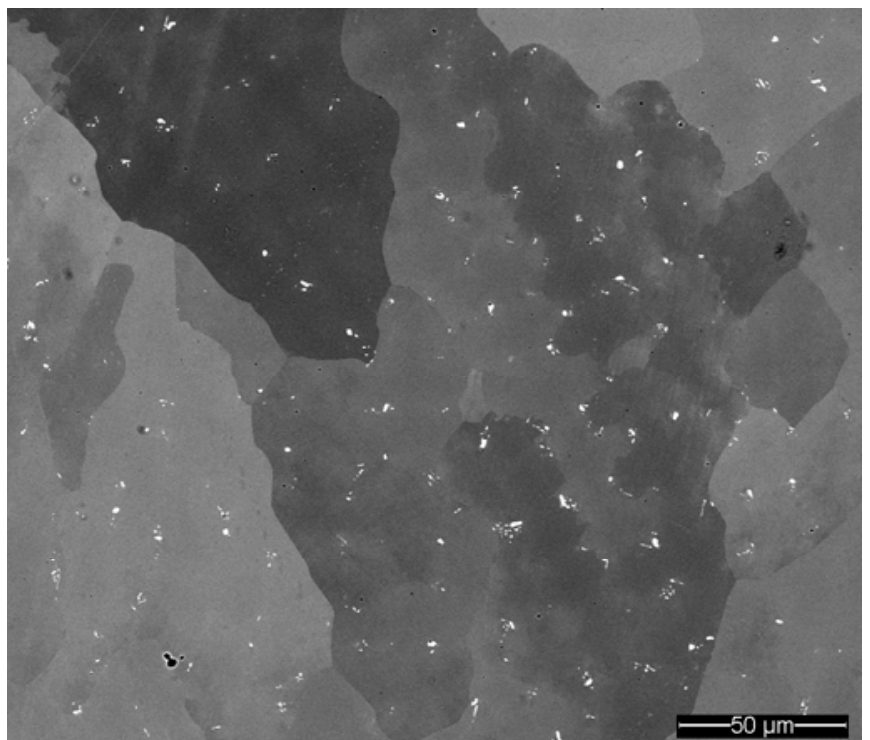

Figure 2. Typical backscatter electron SEM image of the fusion zone. The TCP phase precipitates appear as white.

Prior to creating the collage, a grayscale threshold was applied to each image so that only the brightest pixels remained. Since these pixels corresponded to TCP phase precipitates, the location of these precipitates in the weld is readily identifiable once all the images were joined together.
Contiguous pixels can also then be identified and the size distribution of the TCP phases can be determined.

\section{Microstructure Mapping}

To fully characterize the fusion zone of the weld it was necessary to create a map of the microstructure. To achieve this, automated EBSD was used [12,13], using a TexSEM Laboratories OIM 4 system equipped with a Peltier cooled CCD camera. The specimen was tilted to $70^{\circ}$ in the SEM chamber, and the electron beam was collimated into a spot (an accelerating voltage of $30 \mathrm{kV}$ and a beam current of $98 \mu \mathrm{A}$ were used for this study). This spot is scanned across the specimen surface in regular steps to form a square grid. At each step, a diffraction pattern is collected and solved (i.e. indexed) to identify the local crystal orientation. The orientation is then saved in the form of three Eulerian angles. At the conclusion of the scan, the resultant data is compiled into a spatial map that is used to display the locations of grains and grain boundaries for comparison to the locations of TCP phase particles.

Due to the size of the weld, the data collection was done using a combination of beam and stage motions with a grid step size of $12 \mu \mathrm{m}$, with a coverage area of approximately $8 \mathrm{~mm}$ by $19.5 \mathrm{~mm}$.

\section{RESULTS}

The joined images are shown in Figures 3 and 4 for the aswelded and solution annealed specimens, respectively. While the grain structure of the weld can be observed, it is not as distinct as that obtained using EBSD, as shown in Figures 5 and 6. In particular, the recrystallization due to solution annealing is more readily observable in Figure 6. Note that the tops of the welds (final passes) are on the left hand side of the figures.

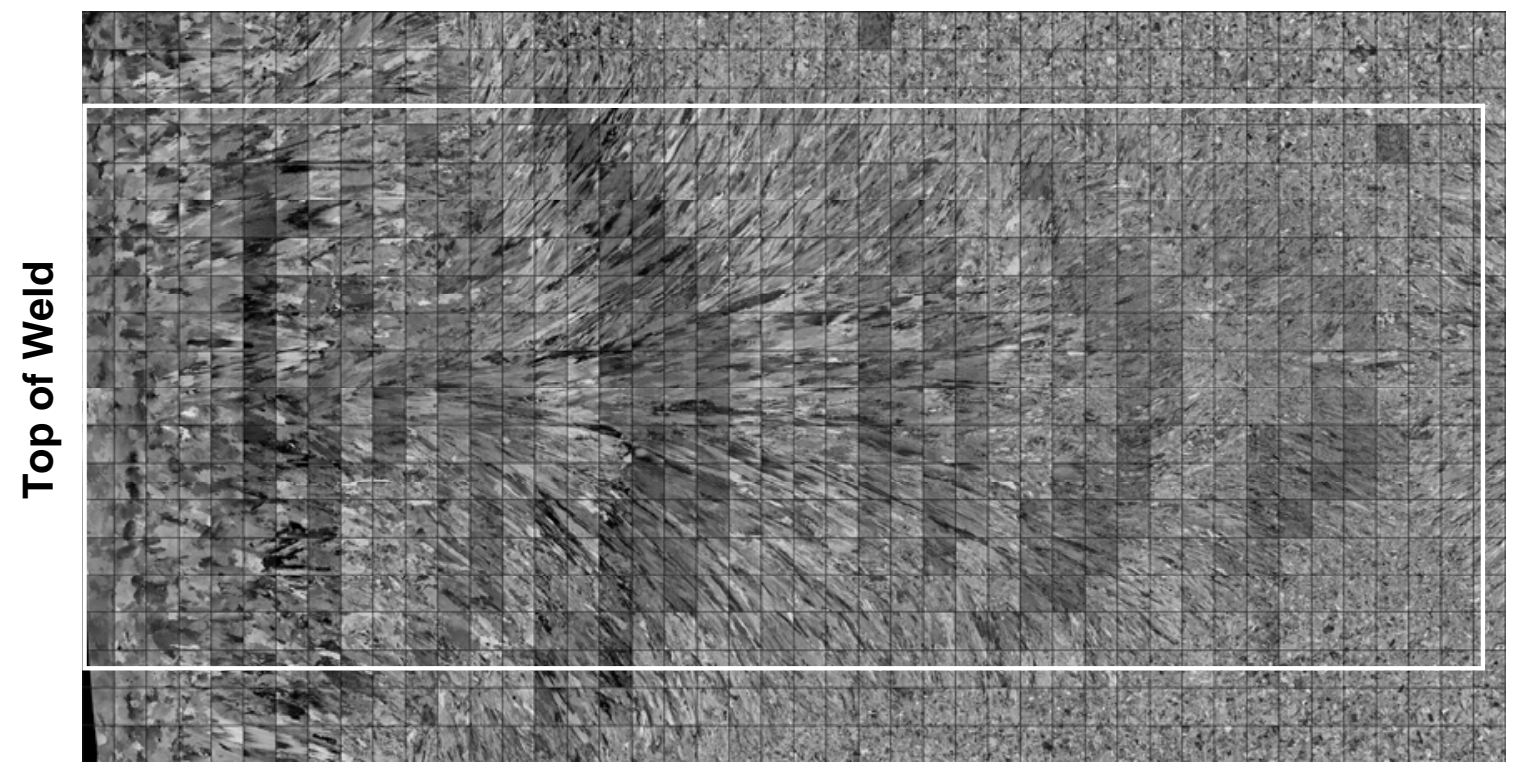

Figure 3. Collage of the fusion zone of the as-welded specimen formed by joining 880 SEM backscatter micrographs. The white box represents the approximate area characterized using EBSD. 


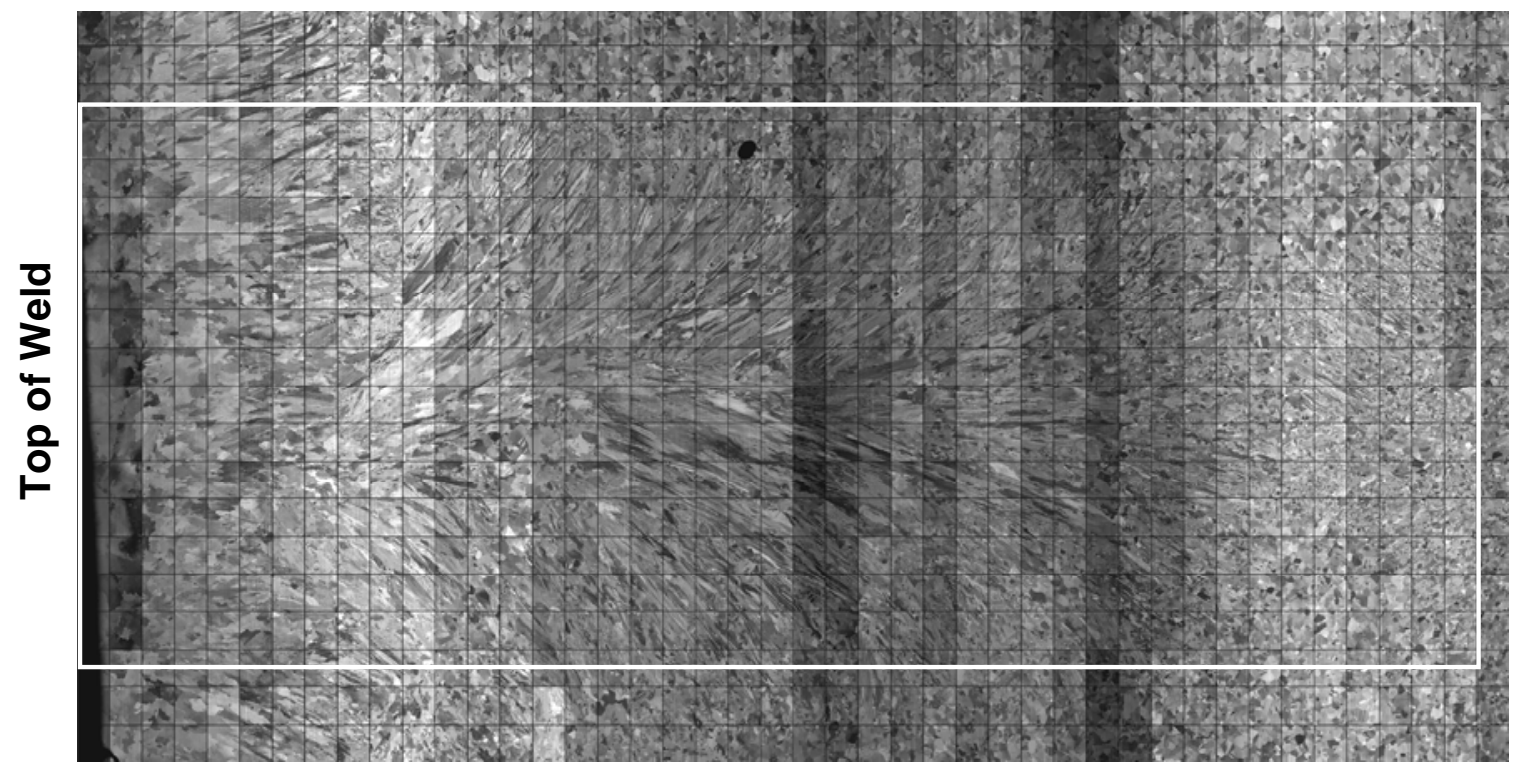

Figure 4. Collage of the fusion zone of the solution annealed $\left(1121^{\circ} \mathrm{C}\right.$ for 20 minutes) specimen formed by joining $880 \mathrm{SEM}$ backscatter micrographs. The white box represents the approximate area characterized using EBSD.

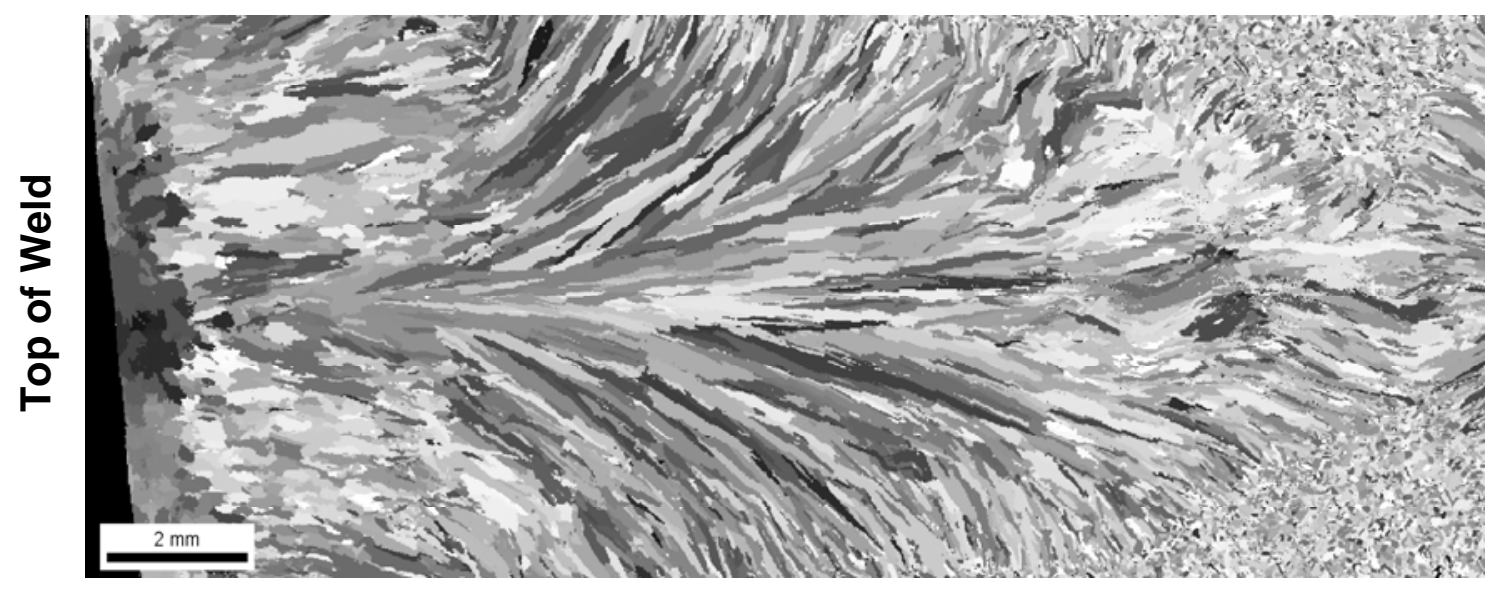

Figure 5. EBSD micrograph of the fusion zone of the as-welded specimen.

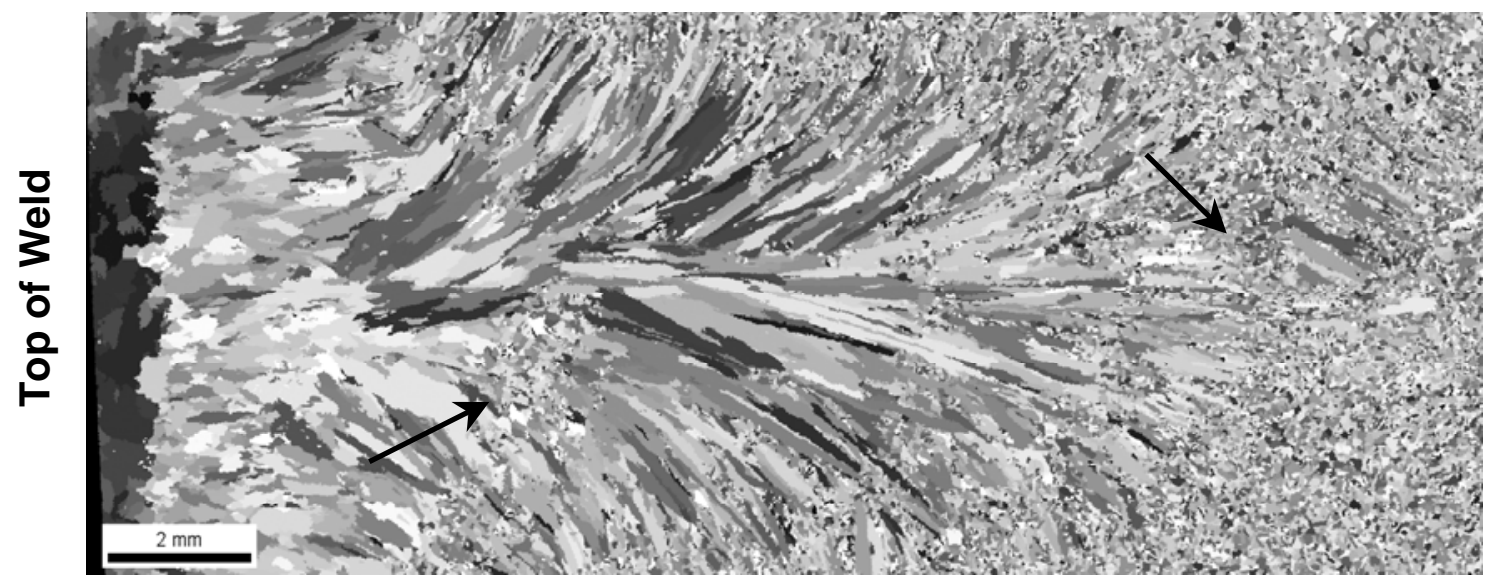

Figure 6. EBSD micrograph of the fusion zone of the solution annealed $\left(1121^{\circ} \mathrm{C}\right.$ for 20 minutes) specimen. Arrows indicate recrystallized regions. 
In Figures 7 and 8, the distribution of TCP precipitates throughout the fusion zones are displayed for the as-welded and solution annealed specimens, respectively. It should be noted that precipitate sizes were artificially coarsened to aid in their visualization in these figures due to their small size. From these figures, two observations can be readily made:

1. The region near the top of the weld has a more uniform distribution of TCP phase precipitates in both the as-welded and solution annealed condition.

2. The distributions of the TCP phase precipitates within the weld clearly follow the weld pass geometry.

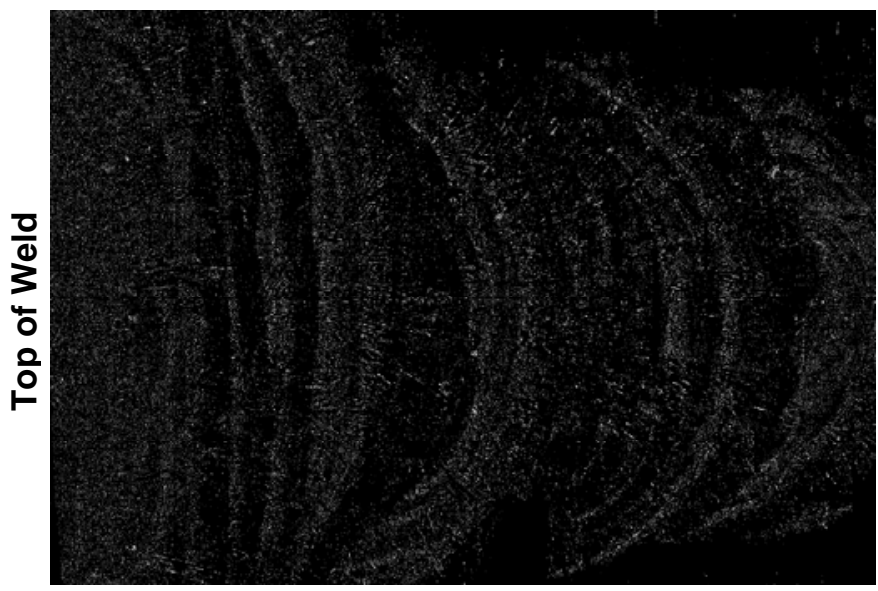

Figure 7. Collage of thresholded backscatter SEM images showing the TCP phase precipitate distribution in the fusion zone of the as-welded specimen.

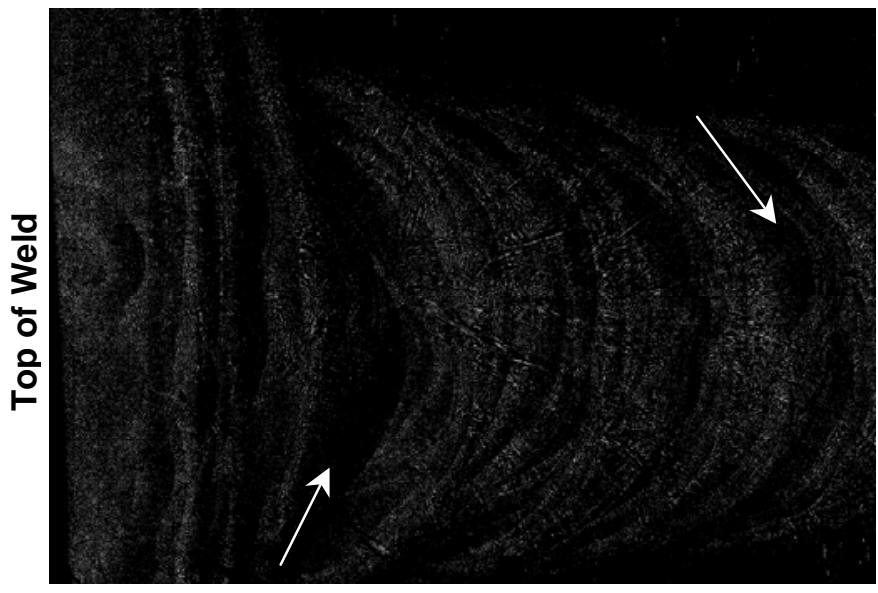

Figure 8. Collage of thresholded backscatter SEM images showing the TCP phase precipitate distribution in the fusion zone of the solution annealed $\left(1121^{\circ} \mathrm{C}\right.$ for 20 minutes) specimen. Arrows indicate recrystallized regions.

For the solution annealed specimen, there are regions with virtually no precipitation present as shown by the arrows in Figure 8. Comparison with Figure 6 reveals a correlation between these regions and the regions of recrystallization (indicated by arrows in both figures). In the regions that do have precipitation, more precipitates are present than in the as- welded condition. This can be explained by investigating the size distribution of the precipitates in both specimens. In Figure 9, the size distribution of the TCP precipitates are plotted as the $\log$ (precipitate count) versus precipitate size in $\mu \mathrm{m}^{2}$. It can be seen that although the distributions for both specimens are similar, there are two key differences.

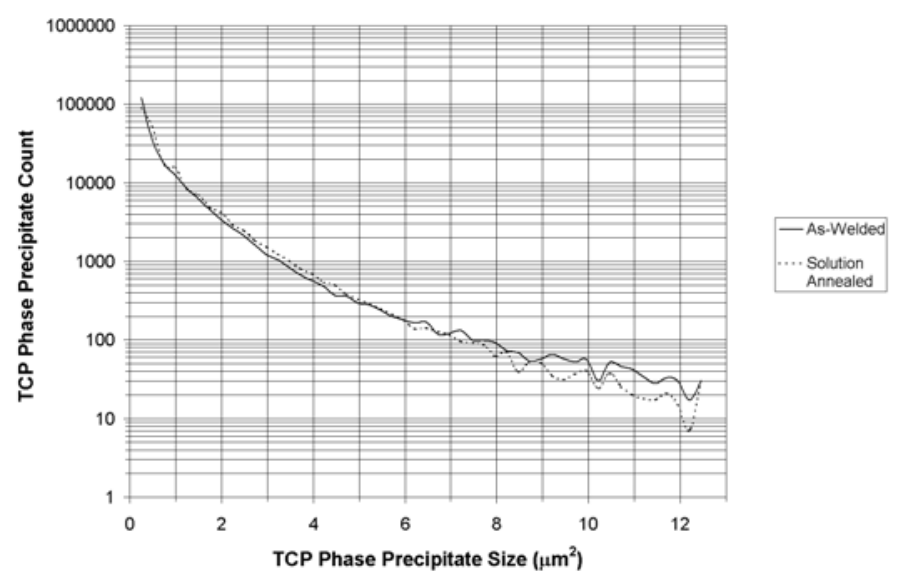

Figure 9. TCP phase precipitate size distribution in the as-welded and solution annealed specimen.

For the smaller precipitate sizes (1 to $5 \mu \mathrm{m}^{2}$ ), more are present in the solution annealed specimen as opposed to the coarser precipitate sizes $\left(>5 \mu \mathrm{m}^{2}\right)$. Considering that there are significantly more small precipitates than coarse ones, this explains the perceived higher density in Figure 8. Calculating the area under the curves reveals that the total amount of TCP phase precipitates in the as-welded condition is approximately $5 \%$ higher than in the solution annealed condition. This then indicates the dissolution of coarse TCP phase precipitates during solution annealing into multiple smaller precipitates.

\section{CONCLUSIONS}

A comparison of the TCP precipitation behavior of thick prototypical welds in the as-welded and solution annealed for 20 minutes at $1121^{\circ} \mathrm{C}$ conditions was conducted. Two specimens were examined in cross-section using EBSD and SEM imaging, one in the as-welded condition and the other in the solution annealed condition, and the observations revealed the following:

- In both specimens, the distribution of TCP phase particles follows the weld pass geometry. Also, the distribution of the TCP phases near the top surface of the weld was determined to be similar in both specimens.

- Areas of recrystallization in the solution annealed specimen correlated to regions depleted of TCP phase precipitates.

- The TCP phase precipitate sizes were generally smaller in the solution annealed condition, although more precipitates were present. Since the total area of TCP phases was reduced by $5 \%$ due to solution annealing, this would indicate that solution annealing is dissolving the TCP phases. 


\section{ACKNOWLEDGMENTS}

Michael M. McGregor and Robert G. Erler are gratefully acknowledged for their assistance in sample treatment and preparation. This work was performed under the auspices of the U. S. Department of Energy by the University of California Lawrence Livermore National Laboratory under contract $\mathrm{N}^{\circ} \mathrm{W}-7405-$ Eng-48. This work is supported by the Yucca Mountain Project, which is part of the Office of Civilian Radioactive Waste Management (OCRWM).

\section{DISCLAIMER}

This document was prepared as an account of work sponsored by an agency of the United States Government. Neither the United States Government nor the University of California nor any of their employees, makes any warranty, express or implied, or assumes any legal liability or responsibility for the accuracy, completeness, or usefulness of any information, apparatus, product, or process disclosed, or represents that its use would not infringe privately owned rights. Reference herein to any specific commercial product, process, or service by trade name, trademark, manufacturer, or otherwise, does not necessarily constitute or imply its endorsement, recommendation, or favoring by the United States Government or the University of California. The views and opinions of authors expressed herein do not necessarily state or reflect those of the United States Government or the University of California, and shall not be used for advertising or product endorsement purposes.

\section{REFERENCES}

[1] Dunn, D., Cragnolino, G., and Sridhar, N., 2000. In Scientific Basis for Nuclear Waste Management XXIII, Materials Research Society, Warrendale, PA, 608, pp. 89.

[2] Rebak, R., Koon, N., Dillman, J., and Crook, P., 2000. Corrosion/2000, NACE International, Houston, TX, Paper 181.

[3] Manning, P., and Schöbel, J, 1986. Werkstoffe und Korrosion, 37, pp. 137.

[4] Asphahani, I., 1989. The Arabian Journal for Science and Engineering, 14, No.2, pp. 317.

[5] Rebak, R., 1998. In Passivity and Localized Corrosion, The Electrochemical Society, Pennington, NJ, 97-26, pp. 1001.

[6] Rebak, R., and Koon, N., 1998. Corrosion/98, NACE International, Houston, TX, Paper 153.

[7] Gruss, K., Cragnolino, G., Dunn, D., and Sridhar, N., 1998. Corrosion/98, NACE International, Houston, TX, Paper 149.

[8] Rebak, R. and Crook, P., 1999. In Critical Factors in Localized Corrosion III, The Electrochemical Society, Pennington, NJ, 98-17, pp. 289.

[9] Cieslak, M.J., Headley, T.J., and Romig, A.D., 1986. Metallurgical Transactions A, 17A, pp. 2035.

[10] Rebak, R., and Crook, P., 2002. In Transportation, Storage, and Disposal of Radioactive Materials, ASME International, New York, NY, PVP-449, pp. 111.
[11] Haynes International, 1997. Hastelloy C-22 Alloy. Kokomo, Indiana, pp. 16.

[12] Wright, S.I., and Adams, B.L., 1992. Metallurgical Transactions A, 23A, pp. 759.

[13] Adams, B.L., Wright, S.I., and Kunze, K., 1993. Metallurgical Transactions A, 24A, pp. 819. 